\title{
Best practices in heterotrophic high-cell-density microalgal processes: achievements, potential and possible limitations
}

\author{
Fabian Bumbak • Stella Cook • Vilém Zachleder • \\ Silas Hauser • Karin Kovar
}

Received: 3 February 2011 /Revised: 13 April 2011 / Accepted: 13 April 2011 /Published online: 13 May 2011

(C) The Author(s) 2011. This article is published with open access at Springerlink.com

\begin{abstract}
Microalgae of numerous heterotrophic genera (obligate or facultative) exhibit considerable metabolic versatility and flexibility but are currently underexploited in the biotechnological manufacturing of known plantderived compounds, novel high-value biomolecules or enriched biomass. Highly efficient production of microalgal biomass without the need for light is now feasible in inexpensive, well-defined mineral medium, typically supplemented with glucose. Cell densities of more than $100 \mathrm{gl}^{-1}$ cell dry weight have been achieved with Chlorella, Crypthecodinium and Galdieria species while controlling the addition of organic sources of carbon and energy in fedbatch mode. The ability of microalgae to adapt their metabolism to varying culture conditions provides opportunities to modify, control and thereby maximise the formation of targeted compounds with non-recombinant microalgae. This review outlines the critical aspects of cultivation technology and current best practices in the heterotrophic high-cell-density cultivation of microalgae. The primary topics include (1) the characteristics of microalgae that make them suitable for heterotrophic cultivation, (2) the appropriate chemical composition of mineral growth media, (3) the different strategies for
\end{abstract}

Dedicated to Professor Thomas Egli on his 60th birthday, in recognition of his invaluable guidance and unfailing inspiration in the field of microbial physiology

F. Bumbak $\cdot$ S. Cook $\cdot$ S. Hauser $\cdot$ K. Kovar $(\square)$ Institute of Biotechnology,

Zurich University of Applied Sciences (ZHAW),

8820, Wädenswil, Switzerland

e-mail: karin.kovar@zhaw.ch

V. Zachleder

Laboratory of Cell Cycles of Algae, Institute of Microbiology of AS CR,

37981, Třeboň, Czech Republic fedbatch cultivations and (4) the principles behind the customisation of biomass composition. The review confirms that, although fundamental knowledge is now available, the development of efficient, economically feasible large-scale bioprocesses remains an obstacle to the commercialisation of this promising technology.

Keywords Microalgae $\cdot$ Heterotrophic growth $\cdot$ High-celldensity culture $\cdot$ Fedbatch process $\cdot$ Substrate limitation . Stirred tank bioreactor

\section{Introduction}

Microalgae, a large and heterogeneous group of microscopic algae, are an almost untapped pool of metabolic versatility. As many of the species occurring in nature have not yet been identified and/or physiologically characterised, their potential awaits exploitation in the biotechnological manufacturing of high-value biomolecules or deliberately enriched biomass (Guedes et al. 2011; Raja et al. 2008; Rosenberg et al. 2008; Wijffels 2008). The term 'microalgae' is typically used in its narrowest sense as a synonym for photoautotrophic, unicellular algae utilising $\mathrm{CO}_{2}$ and gaining energy from light. Although certain species are obligate photoautotrophs, numerous microorganisms currently classified as microalgae are in fact obligate heterotrophs (Droop 1974; Gladue and Maxey 1994), and others are capable of both heterotrophic and photoautotrophic metabolism either sequentially or simultaneously (Chojnacka and Marquez-Rocha 2004; Droop 1974; Gladue and Maxey 1994; Lee 2001).

Heterotrophic cultivation without light and with the controlled addition of an organic source of carbon and energy is similar to procedures established with bacteria or 
yeasts in multipurpose stirred closed tanks sterilised by heat. To date, only a small number of microalgal species have been cultured heterotrophically in conventional bioreactors (Chen 1996; Perez-Garcia et al. 2011). The few commercialised processes in which microalgae are grown under heterotrophic conditions are focussed on the manufacture of polyunsaturated fatty acids (PUFA) in $100-\mathrm{m}^{3}$ scale (Behrens 2005). These biotechnological processes represent a sustainable alternative to the extraction of PUFA from fish oil (Apt and Behrens 1999; Barclay et al. 1994; Barclay 1992; Kyle and Gladue 1991; Kyle et al. 1991; Mendes et al. 2009; Wynn et al. 2005). Several other heterotrophic processes that utilise microalgae have been established at laboratory scale to deliberately enrich the biomass with compounds such as pigments and antioxidants (Pulz and Gross 2004; Raja et al. 2008; Spolaore et al. 2006). L-Ascorbic acid (Running et al. 1994) and polysaccharides (Ramus 1972) are examples of commercially valuable extracellular products obtained from microalgae. Classes of compounds that are found in microalgae and that exhibit desirable properties for treating inflammation, tumours and viral or microbial infections are attracting new interest (Guedes et al. 2011). Moreover, research in the rapidly expanding field of biofuels (Wijffels and Barbosa 2010) provides a valuable source of fundamental information on the physiology and biochemistry of microalgae, producing high-value compounds (e.g. Brányiková et al. 2010; Xiong et al. 2010b). The growing interest in microalgae, either non-recombinant or with appropriate genetic modification (Potvin and Zhang 2010; Specht et al. 2010), suggests that heterotrophic microalgal processes offer significant commercial opportunities (Rosenberg et al. 2008).

In contrast to plants or seaweeds, in which biomass is fairly compact, the harvesting of unicellular microalgae dispersed in natural habitats of microbial consortia is not as straightforward. Low cell densities of several grams per litre are an important cost factor for established production processes with photoautotrophic microalgae in conventional open ponds or photobioreactors (Molina Grima et al. 2003). However, cell densities of more than $100 \mathrm{gl}^{-1}$ cell dry weight, achieved with Chlorella, Crypthecodinium and Galdieria species, highlight the potential of heterotrophic microalgal processes (de Swaaf et al. 2003c; Doucha and Lívanský 2011; Graverholt and Eriksen 2007; Wu and Shi 2007). Moreover, systematic screening for new compounds is only feasible provided that sufficient quantities of concentrated biomass from axenic (pure) cultures are attainable (Olaizola 2003; Wijffels 2008).

From taxonomic studies, it is acknowledged that microalgae exhibit considerable metabolic plasticity (Trainor 2009). In response to their surroundings, particular species can occur in alternative phenotypes, and these can result in the altered formation of metabolites and/or products. Thus, the composition of biomass (or intracellular products) or the production of desired extracellular products is typically affected by culture conditions (Hu 2004; Illman et al. 2000; Jakobsen et al. 2008; Lv et al. 2010; Shi et al. 2006; Xiong et al. 2010b; Yongmanitchai and Ward 1991). In turn, this large environmental adaptability provides opportunities to modify the production of targeted natural compounds and to control their formation at high titres, yields, productivities and the required quality (purity). However, screening the various (natural) phenotypes under different conditions is a complex, time-consuming task involving a large number of culture variables. The basic principles of systematic screening were established during studies of the species suitable for use in aquaculture hatcheries (Gladue and Maxey 1994).

Although the opportunities for heterotrophic processes with microalgae have been considered in several review papers (Apt and Behrens 1999; Borowitzka 1999; Lee 2001 as well as more recently by Eriksen $2008 \mathrm{~b}$ and PerezGarcia et al. 2011), few cover aspects of cultivation technology in depth (e.g. Chen 1996; Chen and Chen 2006). In an attempt to address the outstanding issues, this review paper outlines the current best practices in the heterotrophic high-cell-density cultivation of microalgae for the production of biomass or specific products for health and nutraceutical applications. The main topics dealt with include (1) the characteristics of microalgae suitable for heterotrophic cultivation, (2) the appropriate chemical composition of mineral growth media, (3) strategies for high-cell-density cultivation and (4) the principles of customising biomass composition. Thus, the potential and limitations of fedbatch technology are outlined. The generic process strategies described are based on experimental data collected for non-recombinant microalgae and are, in principle, also applicable to emerging strains improved by genetic engineering.

\section{Cultivation of microalgae in conventional stirred bioreactors}

The microalgal species which are currently attracting commercial interest grow under heterotrophic conditions and perform efficiently in conventional bioreactors in a similar manner to bacteria or yeast (Riesenberg and Guthke 1999). Such sophisticated, safe and controllable bioreactor systems are used to produce novel high-value compounds with microalgae. In contrast, established microalgal products are mostly manufactured by traditional outdoor photoautotrophic technologies (Lee 1997). If a product is unique or is not obtainable in the desired quality or quantity by other means (such as extraction from animal or plant 
material or chemical synthesis), the superior heterotrophic growth characteristics become less critical. Performance losses may also be acceptable in cases where patent infringements need to be prevented. Nevertheless, using microalgae instead of bacteria or yeasts provides the opportunity to establish a new intellectual property claim in the manufacture of competitive products (Borowitzka 1992).

General prerequisites and constraints

In order to be optimally suited for cultivation in conventional stainless steel stirred bioreactors, a particular microalgal species should meet a number of desirable criteria (Table 1). The primary prerequisite is the ability to grow heterotrophically in an inexpensive, well-defined mineral medium with a high degree of resistance to mechanical and chemical stress.

\section{Need for axenic cultures}

An additional crucial prerequisite is the requirement for a monoculture in a long-term bioreactor operation. To date, this is still hampered by the dearth of axenic (pure) cultures of species isolated from the environment. In heterotrophic cultures, the advantage of preventing the growth of contaminants through selective photoautotrophic conditions is not a possibility. Thus, any (minor) contamination introduced with the inoculum could easily outgrow the desired microalgal species.

The particular obstacle can largely be overcome by modern methods of flow cytometry. For example, fluorescence-activated cell sorting permits the efficient differentiation and subsequent isolation of single cells based upon their morphology (size) and variation in autofluorescence (Cellamare et al. 2010; Sensen et al. 1993; Surek and Melkonian 2004). The rate of success for the isolation of axenic microalgal cultures collected from natural habitats was reported to be considerably higher than with a classical approach (Surek and Melkonian 2004). Furthermore, for selectivity reasons and the resulting ease of handling, microalgae such as Galdieria sulpuraria, which perform well at $42{ }^{\circ} \mathrm{C}$ and at a pH of 2 , are desirable.

\section{Restrictions due to high salinity}

Should growth in the presence of sea salt (and thus at a very high salinity of about $35 \mathrm{~g} \mathrm{~kg}^{-1}$ of $\mathrm{Na} / \mathrm{KCl}$ and high osmolarity) be essential for good performance of a particular species, additional investments in vessels coated with special materials like polyether ether ketone are necessary. However, high salinity has not always been

Table 1 Prerequisites, benefits and constraints of heterotrophic cultivation in conventional stirred bioreactors

\begin{tabular}{|c|c|c|}
\hline & Prerequisites/benefits & Constraints \\
\hline $\begin{array}{l}\text { Bioreactor } \\
\text { cultivation }\end{array}$ & $\begin{array}{l}\text { Performance independent of climate } \\
\text { Reduced downstream costs } \\
\text { Enhanced productivity and/or titre } \\
\text { Control of substrate concentrations } \\
\text { Scalable process strategies } \\
\text { Use of multi-purpose bioreactors } \\
\text { Low land requirement } \\
\text { Indoor and cGMP operation }\end{array}$ & $\begin{array}{l}\text { High oxygen demand } \\
\text { Sophisticated substrate feed control } \\
\text { Rheological limitations (at high viscosity) } \\
\text { Critical/toxic levels of metabolites } \\
\text { High costs for (new) equipment }\end{array}$ \\
\hline Culture media & Energy of light not required & $\begin{array}{l}\text { Enhanced risk of contamination (organic carbon } \\
\text { substrate, temperature, } \mathrm{pH} \text { ) }\end{array}$ \\
\hline & $\begin{array}{l}\text { Defined (mineral) and inexpensive } \\
\text { Easy to sterilise } \\
\text { Non-corrosive (low salinity, acidity) } \\
\text { Contamination protection (due to high salinity, extreme pH levels, high } \\
\text { temperature }>40{ }^{\circ} \mathrm{C} \text { ) }\end{array}$ & $\begin{array}{l}\text { Corrosion (high salinity, critical } \mathrm{pH} \text { ) } \\
\text { Expensive ingredients (vitamins, amino acids) } \\
\text { Non-defined composition (e.g. yeast extract) }\end{array}$ \\
\hline Species & $\begin{array}{l}\text { Available as axenic culture } \\
\text { Reasonable specific growth rate } \\
\text { Mechanical resistance } \\
\text { Temperature achievable with conventional cooling }\left(25-40{ }^{\circ} \mathrm{C}\right) \\
\text { Robust and resistant (to long periods of refrigeration, freezing, repeated } \\
\text { cultivation, sudden condition changes) }\end{array}$ & $\begin{array}{l}\text { Surface adhesion } \\
\text { Aggregate formation } \\
\text { Secretion of viscous metabolites } \\
\text { Osmotic stress (at substrate over-dosing) } \\
\text { Intracellular product harvest (hampered by rigid } \\
\text { cell walls) }\end{array}$ \\
\hline
\end{tabular}

Compiled from: Borowitzka 1992; Chen 1996; Doucha and Lívanský 2008 and 2011; Doucha et al. 2009; Gladue and Maxey 1994; Perez-Garcia et al. 2011; Schmidt et al. 2005; Wu and Shi 2008 
linked to increased corrosion of metallic materials (Schmidt et al. 2005). The requirement of marine species for high salt concentrations is sometimes unwittingly overestimated and the salt concentration may be significantly reduced without productivity loss (Kiy et al. 2008). On the other hand, high salt conditions have been found to significantly enhance lipid formation. Upon changing the sodium chloride concentration from 10 to $20 \mathrm{gl}^{-1}$ in a culture of $N$. laevis, the synthesis of total lipids, the production of eicosapentaenoic acid (EPA) and the accumulation of polar lipids increased while the synthesis of neutral lipids decreased (Chen et al. 2008).

Species used in heterotrophic processes

The ability of a number of microalgal species to grow with organic carbon substrates has been demonstrated previously (Droop 1974; Gladue and Maxey 1994). However, the number of current commercially important microalgae that are capable of growth on organic carbon substrates in the dark, and where experience of fedbatch cultivation has been gained, is very limited.

\section{Growth characteristics}

Both the (growth) kinetic and stoichiometric characteristics of these microalgae, along with values for other microalgal species obtained from batch cultures, are summarised in Table 2. This table encompasses fast-growing species with a specific growth rate higher than $0.09 \mathrm{~h}^{-1}$ (e.g. Chlorella, Crypthecodinium, Nitzia, Prototheca spp.) and species that grow at about half the rate, but where a lot of cultivation experience is available (e.g. Galdieria, Haematococcus, Nannochloropsis or Schizochytrium spp.). These specific growth rates correspond to doubling times of between 7 and $15 \mathrm{~h}$. Interestingly, the Chlorella genus exhibits a wide range of growth rates with glucose, which vary with species and growth conditions, such as temperature, $\mathrm{pH}$ or dissolved oxygen concentrations (Shi et al. 2006). The latter condition, in particular, can be controlled in high-celldensity (heterotrophic) cultures as the specific growth rate can be deliberately reduced to assure sufficient oxygen supply (Doucha and Lívanský 2011). Furthermore, heterotrophic growth of Dunaliella sp. and Nannochloropsis sp. is possible but is not practicable due to its very slow growth (Gladue and Maxey 1994).

The specific microalgae's tolerance to certain extracellular substrate concentrations of several grams per litre, as outlined in Table 2, is a feature that also allows particular species to be readily grown to high cell densities in batch culture. Galdieria sulphuraria reached the highest specific growth rates at glucose concentrations of between 2 and $166 \mathrm{gl}^{-1}$, while a glucose concentration of $200 \mathrm{gl}^{-1}$ was regarded as inhibiting its growth (Schmidt et al. 2005). Other highly tolerant species are Schizochytrium and Thraustochytrium, both known to accumulate large quantities of lipids within their biomass (Jain et al. 2007; Kiy et al. 2008). Although Chlorella sp. principally grow at glucose concentrations of more than $60 \mathrm{gl}^{-1}$ (Ip and Chen 2005b), residual concentrations as low as $10 \mathrm{gl}^{-1}$ significantly inhibit their growth (Sansawa and Endo 2004; Wu and Shi 2007; Xiong et al. 2008).

\section{Instigating the photosynthetic apparatus in the dark}

Most of the 'classic' microalgal species are recognised primarily as photoautotrophs. Studies on the effect of repeated (and long-term) propagation in the absence of light and using an organic carbon/energy source for the production of substances involved in the photosynthetic apparatus of microalgae are not yet conclusive (Graverholt and Eriksen 2007; Sansawa and Endo 2004; Shen et al. 2010; Xiong et al. 2010a). Some of these substances continue to be synthesised in the dark, for example, the light-harvesting pigment phycocyanin from $G$. sulphuraria (Eriksen 2008a).

Nevertheless, the inability of obligate photoautotrophs to grow and divide without photosynthetically derived energy is often the main obstacle preventing the efficient heterotrophic production of microalgal metabolites. This can be overcome through appropriate genetic engineering, for example, the introduction of a gene encoding a glucose transporter as demonstrated by Zaslavskaia et al. (2001). Another technically driven means involves exploiting mixotrophic cultures, where microalgal cultures are simultaneously exposed to an organic carbon source and light (Liang et al. 2009; Liu et al. 2009; Chen et al. 2006; Sloth et al. 2006; Feng et al. 2005; Garcia et al. 2005; Ma and Chen 2001). These do, however, require specially constructed illuminated bioreactors. It has also been suggested that light-dependent production can be deliberately induced by 'oxidative stress', triggered by substances other than light (e.g. $\mathrm{H}_{2} \mathrm{O}_{2}$ or $\mathrm{Fe}^{2+}$; Ip and Chen 2005a; Kobayashi et al. 1993).

Composition of culture media and microalgal biomass

Most of the culture media for growing microalgae in vitro have been developed using, as a base, the stoichiometric composition of the microbial biomass grown under regular physiological conditions (Egli 2000; Egli and Fiechter 1981). Information on the composition of microbial biomass in relation to the formation of a particular product is very limited and may vary depending on species and culture conditions. For natural phytoplankton (representing a heterogeneous consortium of microalgae), the proportions of the 


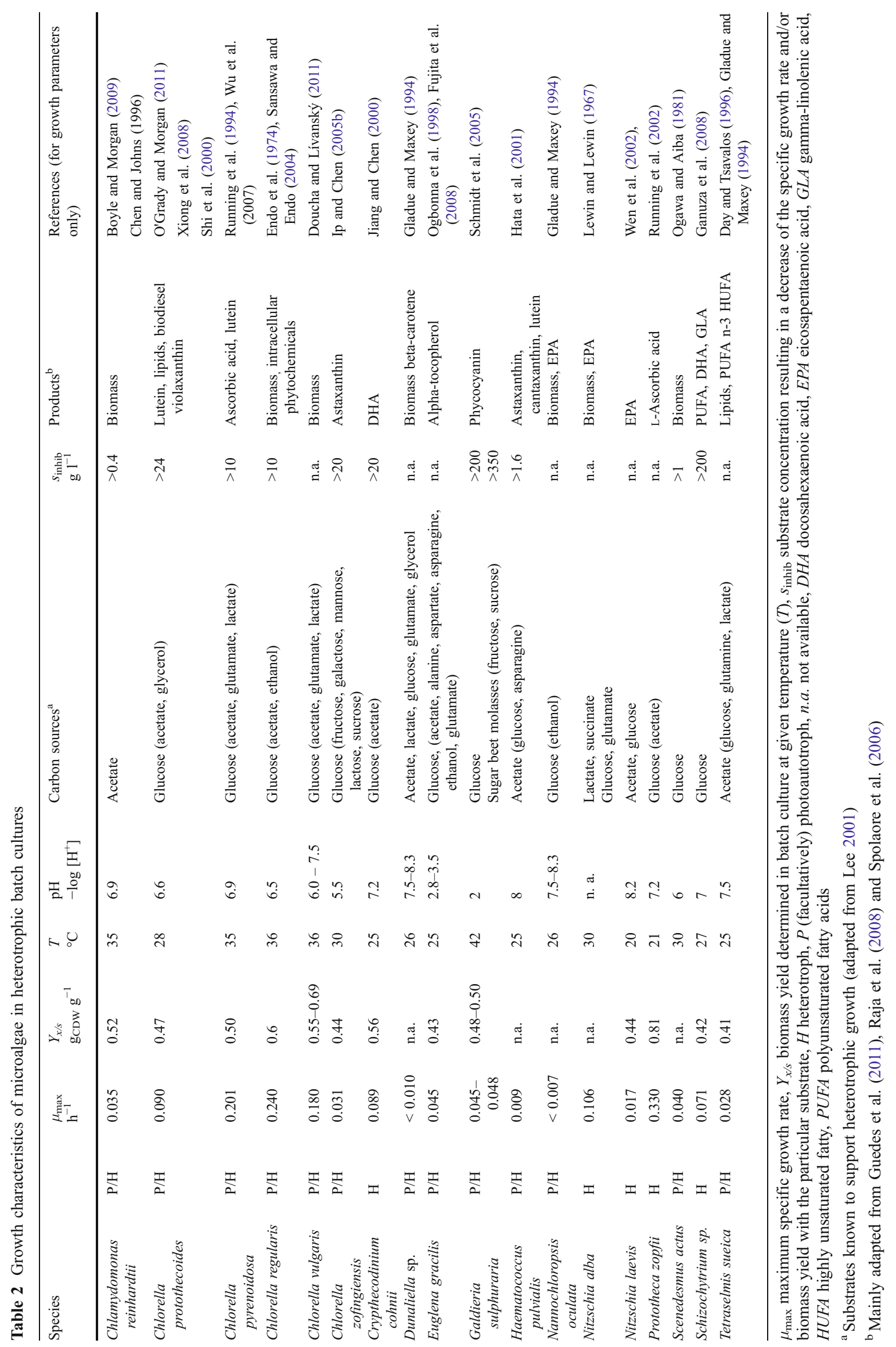


elements are typically derived from the 'Redfield ratio' dating back to 1934, suggesting a molar ratio of $\mathrm{C}_{106} \mathrm{~N}_{16} \mathrm{P}_{1}$ as described in Falkowski (2000). This has recently been further extended to include other important elements (Ho et al. 2003; Quigg et al. 2003). The stoichiometric composition of phytoplankton is comprehensively reviewed by Klausmeier et al. (2008). For heterotrophic cultures of Chlorella vulgaris, a molar stoichiometry of $\mathrm{C}_{3.96} \mathrm{H}_{7.9} \mathrm{O}_{1.875} \mathrm{~N}_{0.685} \mathrm{P}_{0.0539} \mathrm{~K}_{0.036} \mathrm{Mg}_{0.012}$ was determined (Sansawa and Endo 2004), and this has been reflected in optimised media compositions for biomass production in high-cell-density fedbatch processes (e.g. Doucha and Lívanský 2011; Xiong et al. 2008). All of the major molecules in microalgae (i.e. proteins, carbohydrates, lipids) contain carbon as the principal element, with oxygen, hydrogen and nitrogen at lower, or even zero, concentrations (Fig. 1). Typically, in media for heterotrophic cultures that support optimal growth, all of the constituents are supplied in stoichiometric excess to the organic carbon source. Applying stoichiometric principles to an established medium for photoautotrophic cultures of Chlorella spp. (Vonshak 1986), the medium was shown to be deficient in iron, magnesium, sulphur and nitrogen. When optimised, a fivefold increase in biomass concentration was achieved (Mandalam and Palsson 1998).

For most of the microalgal species capable of heterotrophic growth, glucose or acetate is an adequate source of energy and carbon (Table 2; Lee 2004; Lee 2001; PerezGarcia et al. 2011). In addition, low-cost media formulations with molasses or carob pulp syrup, or the waste streams from sugar or milk processing industries, have been successfully used as alternatives to glucose (Mendes et al. 2007; Schmidt et al. 2005). Although microalgae grow with various carbonaceous compounds, glucose is the preferred carbon source because of its ease of handling, accessibility and safety (Lee 2004; Perez-Garcia et al. 2011; Sun et al. 2008). In particular, glucose is used for the production of high-value compounds where the processes need to be reproducible for prospective regulatory approval for pharmaceutical manufacture. Acetate and ethanol are possible alternatives but, because of their respective corrosive effects or high flammability, are only used when an exceptional productivity enhancement is achieved (de Swaaf et al. 2003b; de Swaaf et al. 2003c; Ogbonna et al. 1998). Although the cost of (pure) glucose for microalgal production of high-value compounds is less critical than in the biofuel field, opportunities for valorisation of the biomass after isolation of the target compound are desirable. Examples of such valorisation include the subsequent production of animal and fish feed or its use as an energy-rich biomass for the production of biofuels (Brennan and Owende 2010; Chisti 2007).

Nitrate, ammonia and/or urea are the preferred nitrogen sources at a bioreactor scale (Grobbelaar 2004). Tryptone, glycine and yeast extract have also been evaluated for their potential to enhance growth or product formation (Shen et al. 2010). Moreover, growth data suggest that nitrogen source preference might vary between the species (Shen et al. 2010; Xiong et al. 2008). Yeast extract, a complex component with a high carbon content, is not defined at the single-element level but is frequently used as a source of

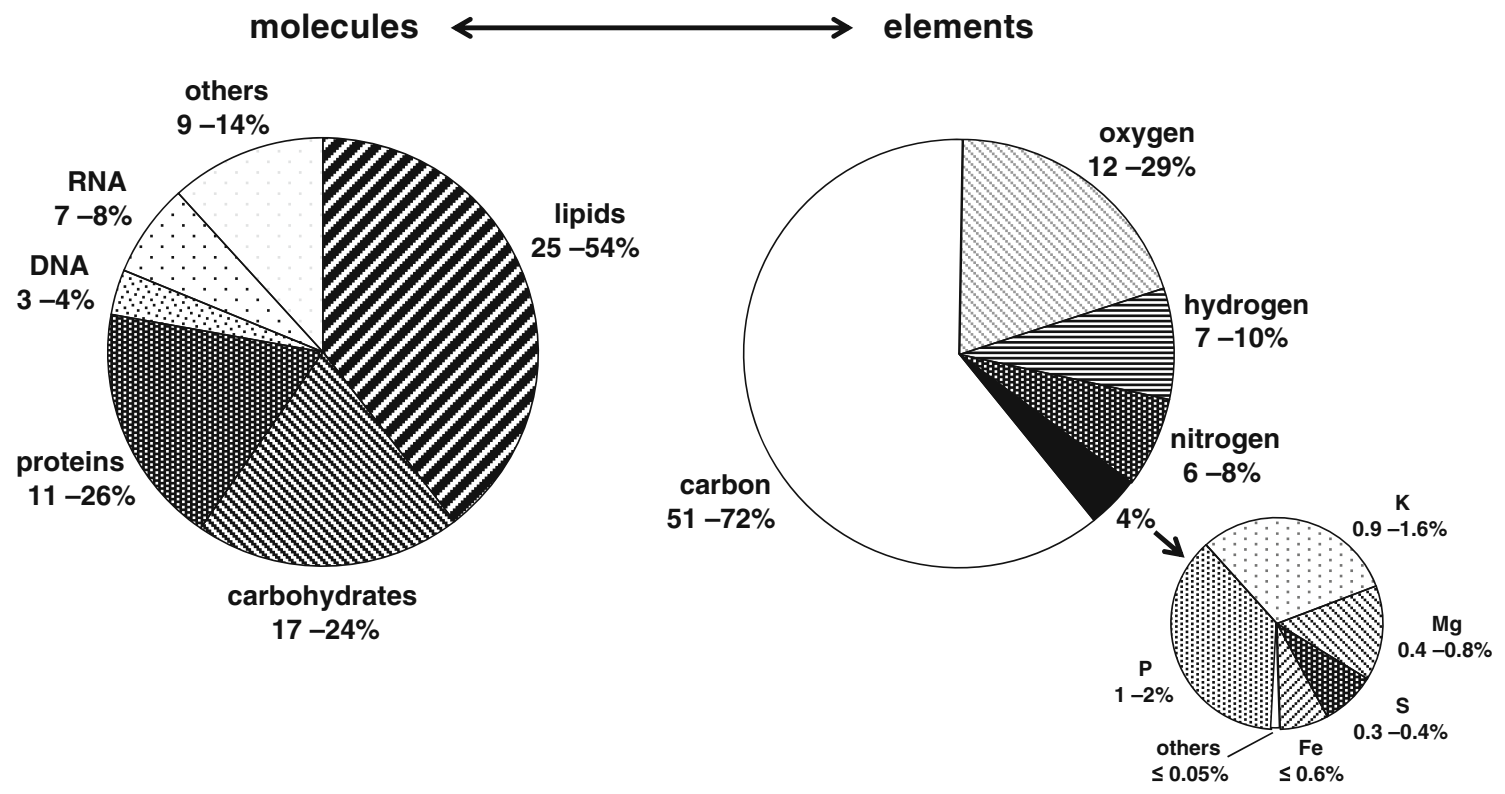

Fig. 1 Compositional variation in Chlorella sp. biomass. Left, molecular composition, lower and upper limits determined at low and high nitrogen availability in heterotrophic cultures of $C$. protothecoides (adapted from Xiong et al. 2010b). Right, proportions of macro and micro elements (adapted from Oh-Hama and Miyachi 1988) 
nitrogen, amino acids, vitamins and trace elements (Grant and Pramer 1962). As its composition varies from lot to lot, supplementation with yeast extract makes precise stoichiometric process control impossible. Moreover, the depletion of some of the components of yeast extract has been shown to result in a linear growth pattern. For example, in a heterotrophic culture with $C$. cohnii, a non-specific nutritional limitation was detected, which coincided with a change from exponential to linear growth while continuously feeding glucose to maintain a residual concentration of between 5 and $20 \mathrm{gl}^{-1}$ (de Swaaf et al. 2003c). It was concluded that nitrogen, solely derived from the yeast extract, was most probably depleted, resulting in the onset of the linear phase, a cessation of cell division and the diversion of added glucose into the accumulation of lipids within the cell.

Furthermore, several microalgae that are grown in pure culture with mineral medium require supplementation with the vitamins cobalamin and/or thiamine (Carvalho et al. 2006; Croft et al. 2005; Droop 2007). In turn, species capable of endogenously synthesising cobalamin need traces of cobalt (Grobbelaar 2004).

\section{High-productivity processes}

The development of appropriate strategies for enhancing biomass and/or product formation is based on understanding (Carvalho et al. 2006; Grobbelaar 2004; Hu 2004) and exploitation of the flexibility (adaptability) of biomass composition within its upper and lower limits as defined by different culture conditions and/or the altered supply of chemical elements in the culture medium. Achieving the desired (optimum) process performance, however, is far from straightforward, as some objectives are by their very nature contradictory (e.g. the highest product titre vs. the shortest process duration, the highest product purity vs. the highest biomass or product formation rates and yields).

High cell densities achieved

In the scientific literature concerning the mass cultivation of microalgae, the term 'high-cell-density culture' (HCD) is ill defined but is generally applied to those values of biomass concentration that fall within the range of the highest values published for photoautotrophic or heterotrophic processes. For a photoautotrophic system, the highest biomass concentration achieved to date is $40 \mathrm{gl}^{-1}$ of cell dry weight (CDW) with thin-layer cultures (Doucha and Lívanský 2006). However, in heterotrophic fedbatch cultures of Chlorella sp. concentrations ranging from approximately $100 \mathrm{gl}^{-1}$ to greater than $150 \mathrm{gl}^{-1} \mathrm{CDW}$ are currently achievable (Table 3; e.g. de Swaaf et al. 2003b; Doucha and
Lívanský 2011; Graverholt and Eriksen 2007; Schmidt et al. 2005; Hauser, unpublished data). Typically, such high cell densities are attainable in fedbatch operation where the increasing biomass is retained and thus accumulates in the bioreactor. A highly concentrated solution of the growth substrate is added in a controlled mode, which in turn determines the specific growth rate and limits the concentration of the residual substrate in the culture broth (e.g. glucose concentration in the feed solution ranging from 100 to $570 \mathrm{gl}^{-1}$, where the highest concentration was used by de Swaaf et al. (2003c)). As the actual data relating to the time courses of the effective (working) culture volume are generally not provided in the publications (Table 3), it is not possible to calculate the amount of biomass produced (in grams) and, thus, the specific growth rates.

Furthermore, biomass concentrations of more than $40 \mathrm{gl}^{-1} \mathrm{CDW}$ have been achieved in batch cultures with the few microalgal genera that tolerate exceptionally high substrate concentrations (Table 2; e.g. Galdieria, Schizochytrium and Thraustochytrium in Schmidt et al. 2005; Jain et al. 2007; Kiy et al. 2008, respectively). For instance, high-cell-density batch cultures with the obligate heterotrophic Prototheca sp. and Aurantiochytrium sp. were described by Running et al. (2002) and Jakobsen et al. (2008), respectively. In the latter, the cell dry weight increased from 40 to $90 \mathrm{gl}^{-1}$ during a post-exponential growth phase while the lipid content of the biomass increased between circa $10 \%$ and $60 \%$. In this context, the term 'biomass growth' needs to be differentiated as either the cells' proliferation due to cell division or an increase in cell mass not directly linked to an increase in cell number.

Do high-cell-density culture and rapid growth imply high productivity?

Although microalgal biomass is the only target in some processes (Becker 2007; Brown et al. 1997; Doucha et al. 2009; Duerr et al. 1998; Tokusoglu and Unal 2003), the apparent prime focus on HCD cultures often obscures the ultimate objective for any microalgal process, which is to achieve the highest product concentration of the desired quality in the shortest possible time. From the basic data summarised in Table 3, the product to biomass yield $\left(Y_{p / x}\right.$, in $\left.\mathrm{g} \mathrm{g}^{-1}\right)$ and the volumetric productivities $\left(r_{x}\right.$ or $r_{p}$, in $\left.\mathrm{g}^{-1} \mathrm{~h}^{-1}\right)$ can be calculated. In principle, however, interpreting productivities that have been computed on the basis of average values for the whole process duration can be misleading.

Maintaining growth at the maximum specific growth rate $\left(\mu\right.$, in $\left.\mathrm{h}^{-1}\right)$ does not often correlate with the highest attainable rate of specific product formation $\left(q_{\mathrm{p}}\right.$, in $\mathrm{g} \mathrm{g}^{-1}$ $\mathrm{h}^{-1}$ ). Generally, the kinetic models accepted of microbial 


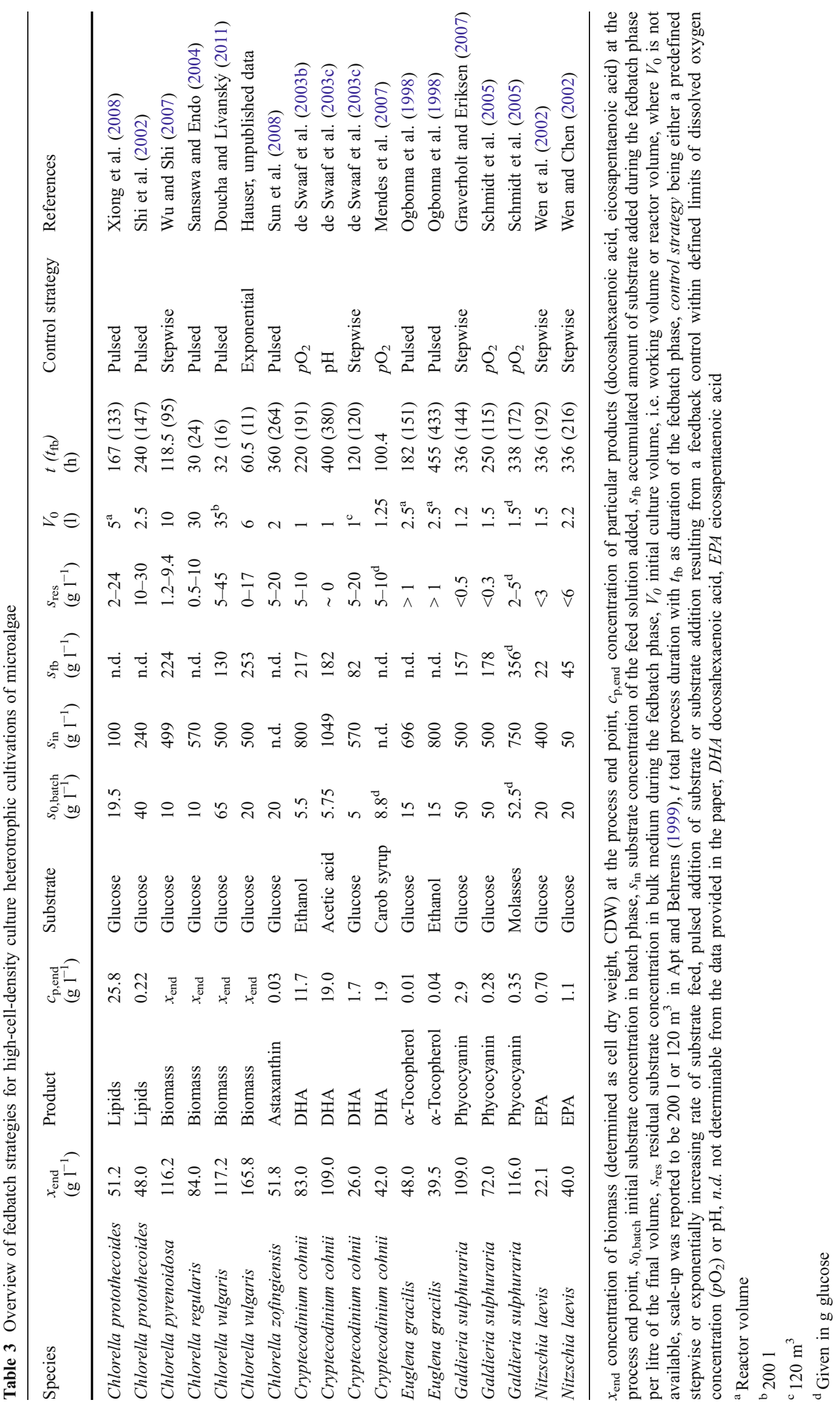


growth association also apply for microalgae. For instance, in continuous cultures, the maximum production of EPA by photoautotrophically grown Nannochloropsis sp. was achieved at dilution rates in the range of $0.004-0.013 \mathrm{~h}^{-1}$ while maximum biomass productivity was obtained at higher dilution rates ranging between 0.011 and $0.017 \mathrm{~h}^{-1}$ (Zou et al. 2000). Similarly, the highest DHA content as well as the highest degree of fatty acid unsaturation of Crypthecodinium cohnii was measured at low glucose concentrations $\left(5 \mathrm{gl}^{-1}\right)$ and thus at a slow growth rate (Jiang and Chen 2000). The formation of EPA by Nitschia laevis in continuous heterotrophic culture was, on the contrary, reported to occur at a higher dilution rate and higher glucose concentration than maximum growth (Wen and Chen 2003). A positive growth association was however reported to apply to the biosynthesis of astaxanthin in Chlorella zofingiensis (Wang and Peng 2008). The above information illustrates that product formation kinetics can fall into either positive or non-/negative growthassociated product formation or a combination of both. Especially in those cases where product formation is not correlated with maximal growth, it is advantageous to have full control over the specific growth rate. In general, such fine-tuning of growth is achieved by the controlled addition of medium constituents in fedbatch cultivation.

Different carbon substrates lead to different biomass/ substrate yields and also affect the formation of the targeted product. As a consequence, maximum product formation does not always correlate with maximum biomass concentration. For instance, in a culture of $C$. cohnii grown with acetic acid, $77 \mathrm{gl}^{-1}$ of biomass and $9.5 \mathrm{gl}^{-1}$ of docosahexaenoic acid (DHA) were harvested after $210 \mathrm{~h}$ (de Swaaf et al. 2003c). In an alternative process strategy using ethanol as the carbon and energy source, less biomass $\left(59 \mathrm{gl}^{-1}\right)$ generated more DHA $\left(10.4 \mathrm{gl}^{-1}\right)$ in a shorter period of time (200 h; de Swaaf et al. 2003b). In another example, Euglena gracilis grown with glucose reached $48 \mathrm{gl}^{-1}$ of biomass and $150 \mu \mathrm{g} \mathrm{g}_{\mathrm{CDW}}{ }^{-1}$ of $\alpha$-tocopherol in $182 \mathrm{~h}$ (Ogbonna et al. 1998). When fed with ethanol, the growth slowed significantly; however, the product yield was enhanced by a factor of approximately 10 , reaching $1,200 \mu \mathrm{g} \mathrm{g}_{\mathrm{CDW}}{ }^{-1}$ and $39.5 \mathrm{gl}^{-1}$ of biomass in $455 \mathrm{~h}$.

As biomass growth slows, for instance, due to the effect of temperature or restricted substrate availability, cell division decelerates and the formation of storage products typically increases simultaneously. PUFA synthesis in certain species, such as eicosapentaenoic acid in Chlorella minutissima, has been reported to occur preferentially at temperatures lower than those required for optimal growth (Yongmanitchai and Ward 1991). However, in the diatom Phaeodactylum tricornutum, maximum product yield and maximum biomass concentration were achieved at the same cultivation temperature between 21.5 and $23{ }^{\circ} \mathrm{C}$. In contrast, the lutein yield $\left(Y_{p / x}\right)$ of heterotrophically grown Chlorella protothecoides was increased from 4.25 to $4.59 \mathrm{mg} \mathrm{g}^{-1}$ by raising the cultivation temperature from 24 to $35^{\circ} \mathrm{C}$ (Shi et al. 2006).

Strategies to enhance productivity in fedbatch cultures

Fedbatch cultivation is the most effective technique for reaching high biomass concentrations in a short time and controlled manner. Typically, this is achieved in cultures grown heterotrophically through controlling the rate of addition of the organic carbon and energy source (i.e. the substrate feed). Varying feed strategies can lead to different efficiencies of biomass and/or product formation.

In contrast to batch mode, osmotic or toxic effects due to high substrate concentrations can be avoided in a fedbatch culture. Moreover, perfusion technology (with cell retention but exchange of culture medium) is appropriate when inhibitory metabolites, which would otherwise affect biomass growth or product formation, need to be removed (Wen and Chen 2002). Auto-inhibition effects have been described in the literature for the cultivation of different species or desired products, such as fatty acids (Bosma et al. 2008; Javanmardian and Palsson 1991; Zou et al. 2000).

The microalgal high-cell-density processes described in the literature (Table 3) employ several different strategies for substrate addition, which are optimised with respect to both the physiological requirements of the particular species and the technical restrictions of the available equipment. The majority of heterotrophic processes employing fedbatch mode, and using microalgae to produce high-value compounds that have been described systematically in recent publications, concentrate on some five to ten species and can be categorised by their target product as follows:

- Polyunsaturated fatty acids, like DHA (Chi et al. 2009; de Swaaf et al. 2003c; Ganuza and Izquierdo 2007) and EPA (Wen and Chen 2002; Wen et al. 2002), using C. cohnii, Nitzschia laevis, Schizochytrium sp. or Ulkenia sp.

- Carotenoids, like astaxanthin (Sun et al. 2008) and lutein (Shi et al. 2002), using Chlorella sp., and tocopherols with E. gracilis (Ogbonna et al. 1998)

- Phycobiliproteins like phycocyanin using G. sulphuraria (Graverholt and Eriksen 2007; Schmidt et al. 2005)

The principal differences of the fedbatch processes listed in Table 2 are (1) the cells' physiological state which is both affected by unrestricted or controlled substrate availability, (2) the limited (since controlled) availability of an element other than carbon and (3) the control strategy, which is either a predefined open-loop control or a feedback control (closed loop). 


\section{Pulsed addition of an organic carbon and energy source}

The pulsed addition of a carbon source is frequently employed in the high-cell-density cultivation of Chlorella sp. (Doucha and Lívanský 2011; Sansawa and Endo 2004; Shi et al. 2002; Sun et al. 2008; Xiong et al. 2008) and has also been applied in processes with E. gracilis (Ogbonna et al. 1998) and G. sulphuraria (Schmidt et al. 2005). Following the depletion of the substrate during an initial batch phase, the residual glucose concentration in the bioreactor is typically maintained within pre-determined upper and lower concentration limits. With $C$. zofingiensis and $C$. protothecoides, the upper limits were set at concentrations of approximately 24 or $30 \mathrm{gl}^{-1}$, respectively. Higher levels would have inhibited biomass growth (Sansawa and Endo 2004; Shi et al. 2002; Sun et al. 2008; Xiong et al. 2008). The pulsed addition of a highly concentrated substrate solution was repeatedly triggered (about five to seven times during the entire process) whenever the glucose concentration dropped below a defined concentration of several grams per litre (Fig. 2). As described in a later section on feedback control strategies, overdosing with substrate can be prevented by implementing an automated dosing strategy based on monitoring the dissolved oxygen concentration.

Pulsed fedbatch strategies are therefore appropriate to species where growth is inhibited by very high substrate concentrations but where residual substrate concentrations of several grams per litre can be tolerated. Biomass is developed at the highest specific growth rates when growth occurs in the continuous presence of an excess of substrate and in a balanced medium. The values for a specific growth rate achieved in such fedbatch processes are comparable to those rates attained during unrestricted, exponential growth in a batch culture (e.g. $\mu_{\max }>0.18 \mathrm{~h}^{-1}$ for C. vulgaris; Doucha and Lívanský 2011). The pulsed fedbatch strategy is applicable to systems required to produce compounds where formation is tightly associated with fast biomass growth. In addition, the combined production strategies can be applied to systems where rapidly built biomass is

Maximal biomass productivity (when growth is unrestricted) due to pulsed substrate addition
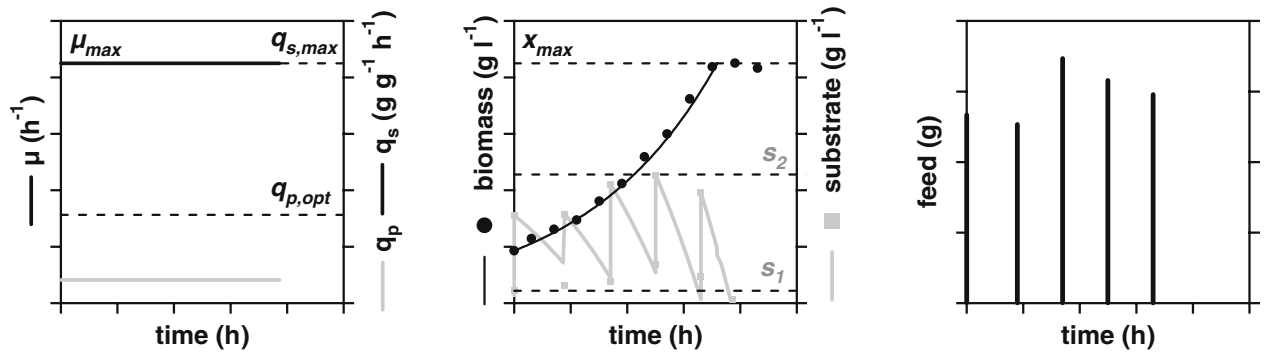

Optimal product formation (when growth is controlled) due to continuous substrate addition

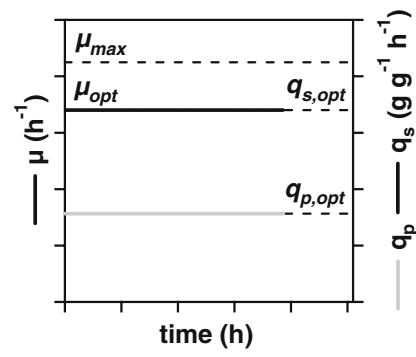

Fig. 2 Principles of controlling growth and product formation through different modes of substrate addition. The three pictograms in each row show (from left to right) the time dependence of the following variables within the fedbatch phase of a bioreactor cultivation of $C$. vulgaris and their maximum ( $\max$ ), minimum (min), optimum (opt) or residual (res) values as indicated by the horizontal dashed lines: specific growth rate $(\mu)$, specific substrate utilisation rate $\left(q_{s}\right)$ and specific product formation rate $\left(q_{p}\right)$; concentrations of biomass $(x)$ and the growth-limiting substrate $(s)$ in the bioreactor, where the substrate concentration in the bioreactor was either determined by pulsed addition at predefined limits $\left(s>s_{1}\right.$ and $s<$ $s_{2}$ ) or reached a residual concentration $\left(s_{\text {res }}\right)$ below which the substrate cannot be utilised at the particular specific growth rate; mode of

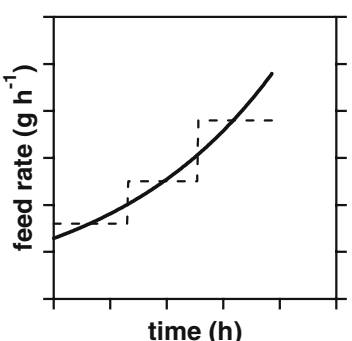

substrate addition. In the left-hand pictograms, growth-associated kinetics of the product formation was applied accordingly to the formula: $q_{\mathrm{p}}=Y_{p / x} \cdot \mu$, where $Y_{p / x}$ is a constant product yield per biomass coefficient. A constant specific growth rate near to its maximum $\left(\mu_{\max }\right)$ and correspondingly exponentially increasing biomass concentration is achieved with pulsed substrate addition (first row, derived from the data of Doucha and Lívanský 2011). With continuous substrate addition and an exponentially increasing feed rate (second row), a desired constant specific growth rate $\left(\mu_{\mathrm{opt}}<\mu_{\max }\right)$ is controlled at the optimum for product formation. To reach near-optimum conditions, the exponential addition can also be approximated by a stepwise increasing feed rate (dashed step-like line) 
essential during the first process phase, prior to a subsequent differently controlled phase that promotes product formation (e.g. Ganuza et al. 2008; Hata et al. 2001).

\section{Continuous addition of an organic carbon and energy source}

Potential strategies for continuous substrate addition are usually categorised using mathematical functions that describe the time dependence of the rate of substrate addition (i.e. the feed profile). Such strategies encompass substrate addition at constant or predefined rates. Predefined rates can increase or decrease following linear or exponential functions or by equivalent, stepwise approximations (Fig. 2). However, the only feed profiles that are currently used to grow microalgae are those with stepwise increasing or decreasing feed rates (for example, Chlorella, Crypthecodinium, Galdieria and Nitzschia by $\mathrm{Wu}$ and Shi (2007), de Swaaf et al. (2003b), Graverholt and Eriksen (2007) and Wen and Chen (2002), respectively).

The optimum feed profile for product formation can be determined by using a rational approach provided that the effect of appropriate control variables (including $\mu$ ) on the targeted productivity has been quantified and, preferably, captured in a model (Wu and Shi 2007; Zhang et al. 1999a; Zhang et al. 1999b; Zhang et al. 1999c). In addition, models based on hybrid neural networks can be used to predict optimum fedbatch strategies. A feed profile that included an exponentially increasing glucose addition over several steps, each at a constant feed rate, was successfully applied to a Chlorella pyrenoidosa culture to attain a biomass concentration of $116 \mathrm{gl}^{-1}$ at an average productivity of $1.02 \mathrm{gl}^{-1} \mathrm{~h}^{-1}$ (Wu and Shi 2007). Similarly, with a culture of G. sulphuraria, the feed rate was increased up to 3.7 times in one step per day, achieving $27.8 \mathrm{gl}^{-1}$ of biomass and an average productivity of approximately $0.33 \mathrm{gl}^{-1} \mathrm{~h}^{-1}$ (Graverholt and Eriksen 2007). Following an initial batch culture, the substrate was continuously added at a specific rate, which was lower than the specific glucose utilisation rate required to support the biomass, i.e. a $\mu_{\max }$ of $0.053 \mathrm{~h}^{-1}$. Residual glucose concentrations were maintained below $0.5 \mathrm{gl}^{-1}$ and the specific growth rate was controlled at $0.046 \mathrm{~h}^{-1}$ during the fedbatch phase.

Specific growth rate can be controlled at a particular defined rate, lower than its maximum, by continuous (preferably exponential) substrate addition. This allows product formation to be enhanced when its optimum is not linked to the fastest biomass growth (as illustrated in the pictograms in Fig. 2). However, the strategy of controlling the $\mu$ at a certain (optimum) value as demonstrated with bacteria and yeast has not yet been described in the literature on microalgae.
Substrate addition determined by feedback control

A feedback control strategy allows a continuous adaptation of the rate of substrate addition based on physiological criteria, such as the production of acids or bases (de Swaaf et al. 2003c), or oxygen utilisation (de Swaaf et al. 2003b; Schmidt et al. 2005). The changes in $\mathrm{pH}$ and $p \mathrm{O}_{2}$ values resulting from biomass growth (or product formation) are countered up to a predefined value.

In an auxostat-fedbatch system with Schizochyrium sp., the $\mathrm{pH}$ was continuously controlled at a value of 7 through the addition of ammonium hydroxide solution (Ganuza et al. 2008). In this manner, both $\mathrm{pH}$ and an excess of nitrogen were controlled while the growth of the biomass reflected the utilisation of the carbon substrate. The substantial technical benefit of such a system is the potential to replace the ammonium hydroxide solution used for $\mathrm{pH}$ control with a potassium hydroxide solution. In this way, the desired onset of the production of lipids (DHA) is readily triggered through nitrogen deprivation (i.e. the nitrogen level decreases to zero from the concentration accumulated during the ammonium hydroxide addition phase). Effectively, this process strategy is fedbatch with respect to the nitrogen addition but is batch with respect to the (carbon) growth substrate. In a fedbatch process producing DHA with C. cohnii (de Swaaf et al. 2003b), the acetic acid used as the carbon/energy substrate was added via a $\mathrm{pH}$ control system to maintain a $\mathrm{pH}$ of 6.5 . This resulted in the continuous addition of acetic acid at a rate which followed a time course determined by the metabolic requirements of the biomass.

Feedback control based on the dissolved oxygen concentration $\left(p \mathrm{O}_{2}\right.$ or $\left.\mathrm{DO}\right)$ is another process strategy that is technically feasible to prevent overdosing of the substrate. As determination of the residual concentration of the substrate typically involves a time delay, monitoring the decrease/ increase in $\mathrm{pO}_{2}$ has the advantage such that the pulsed addition of substrate can be appropriately timed (Schmidt et al. 2005).

Strategies for customising biomass composition by adapting the culture medium

The following strategies, potentially combined with fedbatch culture, allow product formation or biomass composition to be further controlled:

- Controlling the availability of components in the growth medium other than carbon

- Replacing a medium component with an alternative (e.g. using a different carbon or nitrogen source or exchanging sulphur with selenium) 
- Adapting the culture conditions (for example, $T, p \mathrm{O}_{2}$, $\mathrm{pH}$ ) to conditions that would typically be outside of the optimal range for biomass growth

\section{Affecting the proportions of macromolecules within the biomass}

Biomass composition can be customised and/or product formation can be enhanced through tailoring the composition of the culture medium. The latter is achieved by controlling the consumption of a particular element through ensuring that its supply and, thus, availability are limited. An example of this principle is seen in the range of biomass composition achievable with $C$. protothecoides (Fig. 1).

Lipid content has been reported to increase under nutrient-deprived conditions such as low concentrations of nitrogen (Griffiths and Harrison 2009; Hsieh and Wu 2009; Illman et al. 2000; Jakobsen et al. 2008; Lv et al. 2010; Lynn et al. 2000; Rodolfi et al. 2009; Widjaja et al. 2009; Yongmanitchai and Ward 1991), phosphorus (Lynn et al. 2000; Reitan et al. 1994; Rodolfi et al. 2009) and silicon (Griffiths and Harrison 2009; Lynn et al. 2000). Low nitrogen concentrations were also reported to increase the cellular contents of lutein in C. protothecoides (Shi et al. 2002) and astaxanthin in C. zofingiensis (Ip and Chen 2005b).

$\mathrm{N}$-deprivation regimes are most frequently expressed as the molar carbon-to-nitrogen (C-to-N) ratio (Ip and Chen 2005b; Shi et al. 2002; Sloth et al. 2006; Wen et al. 2002). Grown at a high C-to-N ratio, the cell dry mass of $C$. protothecoides contained up to $53.8 \%$ lipids compared to $25.2 \%$ obtained in low C-to-N medium. This lipid increase was accompanied by a drop in protein content from $25.8 \%$ at low C-to-N to $10.5 \%$ at a high C-to-N ratio (Xiong et al. 2010b).

\section{Biomass enrichment by replacing its constituents}

The enrichment of the microalgal biomass with (readily bio-available) selenium at extraordinarily high volumetric productivities and final concentrations $(>0.4 \mathrm{mg}$ Se per gram of biomass) is governed by a different mechanism than the enrichment by lipids. Microalgae, which are grown in medium containing a lower-than-stoichiometrically-required concentration of sulphur, are exposed to inorganic selenium in the form of selenite. Depending on the algae species, the cells are capable of incorporating the element at different levels, preferentially into intracellular protein, e.g. C. vulgaris or Scenedesmus quadricauda in Doucha et al. (2009) and Umysová et al. (2009), respectively.

\section{Conclusions and future trends}

Recent advances in microalgal biotechnology have created opportunities for the efficient production of high-value (natural) compounds with the properties of plant-derived products that provide unique benefits (e.g. plant-like glycosylation) compared to their analogues resulting from chemical synthesis or recombinant microorganisms. The laboratory-scale bioreactor cultivations included within this review provide a first insight into the feasibility of carrying out heterotrophic processes with microalgae at an industrial scale. These processes have, in part, already been commercialised with the biotechnological production of PUFA. (To date, the authors are not aware of any literature on the heterotrophic large-scale fedbatch cultivation of microalgae, in contrast to literature on batch cultivation referred to by Apt and Behrens 1999; Behrens 2005; Wynn et al. 2005). This review confirms that the development of efficient, economically feasible large-scale bioprocesses remains an obstacle to the commercialisation of the promising microalgae technology.

The generic cultivation strategies outlined are based on the experimental data of natural microalgae but, in principle, could also be applied to emerging strains improved by genetic engineering. Fundamental knowledge enabling strain design may be derived from advanced metabolic flux analyses (Xiong et al. 2010b). A promising new avenue for transgenic microalgae is developing based on the knowledge gained over the past two decades, which includes the complete sequencing of the first microalgal genomes (Leon-Banares et al. 2004; Parker et al. 2008; Rosenberg et al. 2008; Walker et al. 2005a; Walker et al. 2005b).

Acknowledgements The authors wish to thank Christian Meier and Katerina Bisova for their generous help in collecting and evaluating the wealth of information available. In particular, Petr Hyka, Dominik Lüthy and Ganna Aleshcheva are acknowledged for spending considerable time on designing and finalising the drawings and Michael Cook for critical proofreading.

Open Access This article is distributed under the terms of the Creative Commons Attribution Noncommercial License which permits any noncommercial use, distribution, and reproduction in any medium, provided the original author(s) and source are credited.

\section{References}

Apt KE, Behrens PW (1999) Commercial developments in microalgal biotechnology. J Phycol 35(2):215-226

Barclay WR (1992) Process for the heterotrophic production of microbial products with high concentrations of omega-3 highly saturated fatty acids. US Patent 5,130,242

Barclay WR, Meager KM, Abril JR (1994) Heterotrophic production of long-chain omega-3-fatty-acids utilizing algae and algae-like microorganisms. J Appl Phycol 6(2):123-129 
Becker EW (2007) Micro-algae as a source of protein. Biotechnol Adv 25(2):207-210. doi:10.1016/j.biotechadv.2006.11.002

Behrens PW (2005) Photobioreactors and fermentors: the light and dark sides of growing algae. In: Andersen RA (ed) Algal culturing techniques. Elsevier, Oxford, pp 189-204

Borowitzka MA (1992) Algal biotechnology products and processes-matching science and economics. J Appl Phycol 4 (3):267-279

Borowitzka MA (1999) Commercial production of microalgae: ponds, tanks, tubes and fermenters. J Biotechnol 70(1-3):313321

Bosma R, Miazek K, Willemsen SM, Vermue MH, Wijffels RH (2008) Growth inhibition of Monodus subterraneus by free fatty acids. Biotechnol Bioeng 101(5):1108-1114. doi:10.1002/ Bit.21963

Boyle NR, Morgan JA (2009) Flux balance analysis of primary metabolism in Chlamydomonas reinhardtii. BMC Syst Biol 3:4. doi:10.1186/1752-0509-3-4

Brányiková I, Maršálková $\mathrm{B}$, Doucha $\mathrm{J}$, Brányik T, Bišová $\mathrm{K}$, Zachleder V, Vítová M (2010) Microalgae-novel highly efficient starch producers. Biotechnol Bioeng. doi:10.1002/ bit.23016

Brennan L, Owende P (2010) Biofuels from microalgae - a review of technologies for production, processing, and extractions of biofuels and co-products. Renewable Sustainable Energy Rev 14(2):557-577. doi:10.1016/j.rser.2009.10.009

Brown MR, Jeffrey SW, Volkman JK, Dunstan GA (1997) Nutritional properties of microalgae for mariculture. Aquaculture 151(14):315-331

Carvalho AP, Pontes I, Gaspar H, Malcata FX (2006) Metabolic relationships between macro- and micronutrients, and the eicosapentaenoic acid and docosahexaenoic acid contents of Pavlova lutheri. Enzyme Microb Technol 38(3-4):358-366. doi:10.1016/j.enzmictec.2005.05.014

Cellamare M, Rolland A, Jacquet S (2010) Flow cytometry sorting of freshwater phytoplankton. J Appl Phycol 22(1):87-100. doi:10.1007/s10811-009-9439-4

Chen F (1996) High cell density culture of microalgae in heterotrophic growth. Trends Biotechnol 14(11):421-426

Chen GQ, Chen F (2006) Growing phototrophic cells without light. Biotechnol Lett 28(9):607-616. doi:10.1007/s10529-006-0025-4

Chen TF, Zheng WJ, Wong YS, Yang F, Bai Y (2006) Accumulation of selenium in mixotrophic culture of Spirulina platensis on glucose. Bioresour Technol 97(18):2260-2265

Chen GQ, Jiang Y, Chen F (2008) Salt-induced alterations in lipid composition of diatom Nitzschia laevis (Bacillariophyceae) under heterotrophic culture condition. J Phycol 44(5):1309-1314. doi:10.1111/j.1529-8817.2008.00565.x

Chi ZY, Liu Y, Frear C, Chen SL (2009) Study of a two-stage growth of DHA-producing marine algae Schizochytrium limacinum SR21 with shifting dissolved oxygen level. Appl Microbiol Biotechnol 81(6):1141-1148. doi:10.1007/s00253-008-1740-7

Chisti Y (2007) Biodiesel from microalgae. Biotechnol Adv 25 (3):294-306. doi:10.1016/j.biotechadv.2007.02.001

Chojnacka K, Marquez-Rocha F-J (2004) Kinetic and stoichiometric relationships of the energy and carbon metabolism in the culture of microalgae. Biotechnology 3(1):21-34

Croft MT, Lawrence AD, Raux-Deery E, Warren MJ, Smith AG (2005) Algae acquire vitamin B12 through a symbiotic relationship with bacteria. Nature 438(7064):90-93. doi:10.1038/ nature 04056

Day JG, Tsavalos AJ (1996) An investigation of the heterotrophic culture of the green alga Tetraselmis. J Appl Phycol 8(1):73-77

de Swaaf ME, de Rijk TC, van der Meer P, Eggink G, Sijtsma L (2003a) Analysis of docosahexaenoic acid biosynthesis in Crypthecodinium cohnii by $\mathrm{C}-13$ labelling and desaturase inhibitor experiments. J Biotechnol 103(1):21-29. doi:10.1016/ S0168-1656(03)00070-1

de Swaaf ME, Pronk JT, Sijtsma L (2003b) Fed-batch cultivation of the docosahexaenoic-acid-producing marine alga Crypthecodinium cohnii on ethanol. Appl Microbiol Biotechnol 61(1):40-43. doi:10.1007/s00253-002-1118-1

de Swaaf ME, Sijtsma L, Pronk JT (2003c) High-cell-density fedbatch cultivation of the docosahexaenoic acid producing marine alga Crypthecodinium cohnii. Biotechnol Bioeng 81(6):666-672. doi:10.1002/Bit.10513

Doucha J, Lívanský K (2006) Productivity, $\mathrm{CO}_{2} / \mathrm{O}^{-2}$ exchange and hydraulics in outdoor open high density microalgal (Chlorella sp.) photobioreactors operated in a Middle and Southern European climate. J Appl Phycol 18(6):811-826. doi:10.1007/ s10811-006-9100-4

Doucha J, Lívanský K (2008) Influence of processing parameters on disintegration of Chlorella cells in various types of homogenizers. Appl Microbiol Biotechnol 81(3):431-440

Doucha J, Lívanský K (2011) Production of high-density Chlorella culture grown in fermenters. J Appl Phycol. doi:10.1007/s10811010-9643-2

Doucha J, Lívanský K, Kotrbáček V, Zachleder V (2009) Production of Chlorella biomass enriched by selenium and its use in animal nutrition: a review. Appl Microbiol Biotechnol 83(6):1001-1008. doi:10.1007/s00253-009-2058-9

Droop MR (1974) Heterotrophy of carbon. In: Stewart WDP (ed) Algal physiology and biochemistry. Blackwell, Oxford, pp 530 559

Droop MR (2007) Vitamins, phytoplankton and bacteria: symbiosis or scavenging? J Plankton Res 29(2):107-113. doi:10.1093/plankt/ fbm009

Duerr EO, Molnar A, Sato V (1998) Cultured microalgae as aquaculture feeds. J Mar Biotechnol 6(2):65-70

Egli T (2000) Nutrition of microorganisms. Encyclopedia of Microbiology 3:431-447

Egli T, Fiechter A (1981) Theoretical-analysis of media used in the growth of yeasts on methanol. J Gen Microbiol 123:365369

Endo H, Nakajima K, Chino R, Shirota M (1974) Studies on Chlorella regularis heterotrophic fast growing strain. 1. Growthcharacteristics and cellular components of Chlorella regularis, heterotrophic fast growing strain. Agric Biol Chem 38(1):9-18

Eriksen NT (2008a) Production of phycocyanin - a pigment with applications in biology, biotechnology, foods and medicine. Appl Microbiol Biotechnol 80(1):1-14. doi:10.1007/s00253-0081542-y

Eriksen NT (2008b) The technology of microalgal culturing. Biotechnol Lett 30(9):1525-1536. doi:10.1007/s10529-008-9740-3

Falkowski PG (2000) Rationalizing elemental ratios in unicellular algae. J Phycol 36(1):3-6

Feng FY, Yang W, Jiang GZ, Xu YN, Kuang TY (2005) Enhancement of fatty acid production of Chlorella sp (Chlorophyceae) by addition of glucose and sodium thiosulphate to culture medium. Process Biochem 40(3-4):1315-1318. doi:10.1016/j.proc bio.2004.06.011

Fujita T, Aoyagi H, Ogbonna JC, Tanaka H (2008) Effect of mixed organic substrate on alpha-tocopherol production by Euglena gracilis in photoheterotrophic culture. Appl Microbiol Biotechnol 79(3):371-378. doi:10.1007/s00253-008-1443-0

Ganuza E, Izquierdo MS (2007) Lipid accumulation in Schizochytrium G13/2S produced in continuous culture. Appl Microbiol Biotechnol 76(5):985-990. doi:10.1007/s00253-007-1019-4

Ganuza E, Anderson AJ, Ratledge C (2008) High-cell-density cultivation of Schizochytrium sp in an ammonium/pH-auxostat fed-batch system. Biotechnol Lett 30(9):1559-1564. doi:10.1007/s10529-008-9723-4 
Garcia MCC, Miron AS, Sevilla JMF, Grima EM, Camacho FG (2005) Mixotrophic growth of the microalga Phaeodactylum tricornutum - influence of different nitrogen and organic carbon sources on productivity and biomass composition. Process Biochem 40(1):297-305. doi:10.1016/j.proc bio.2004.01.016

Gladue RM, Maxey (1994) Microalgal feeds for aquaculture. J Appl Phycol 6(2):131-141

Grant CL, Pramer D (1962) Minor element composition of yeast extract. J Bacteriol 84:869-870

Graverholt OS, Eriksen NT (2007) Heterotrophic high-cell-density fed-batch and continuous-flow cultures of Galdieria sulphuraria and production of phycocyanin. Appl Microbiol Biotechnol 77 (1):69-75. doi:10.1007/s00253-007-1150-2

Griffiths MJ, Harrison STL (2009) Lipid productivity as a key characteristic for choosing algal species for biodiesel production. J Appl Phycol 21(5):493-507. doi:10.1007/s10811-0089392-7

Grobbelaar JU (2004) Algal nutrition: mineral nutrition. In: Richmond A (ed) Handbook of microalgal culture: biotechnology and applied phycology. Blackwell, Oxford, pp 97-115

Guedes AC, Amaro HM, Malcata FX (2011) Microalgae as sources of high added-value compounds - a brief review of recent work. Biotechnol Prog. doi:10.1002/btpr.575

Hata N, Ogbonna JC, Hasegawa Y, Taroda H, Tanaka H (2001) Production of astaxanthin by Haematococcus pluvialis in a sequential heterotrophic-photoautotrophic culture. J Appl Phycol 13(5):395-402

Ho TY, Quigg A, Finkel ZV, Milligan AJ, Wyman K, Falkowski PG, Morel FMM (2003) The elemental composition of some marine phytoplankton. J Phycol 39(6):1145-1159

Hsieh C-H, Wu W-T (2009) Cultivation of microalgae for oil production with a cultivation strategy of urea limitation. Bioresour Technol 100:3921-3926. doi:10.1016/j.biortech.2009.03.019

$\mathrm{Hu}$ Q (2004) Environmental effects on cell composition. In: Richmond A (ed) Handbook of microalgal culture: biotechnology and applied phycology. Blackwell, Oxford, pp 83-94

Illman AM, Scragg AH, Shales SW (2000) Increase in Chlorella strains calorific values when grown in low nitrogen medium. Enzyme Microb Technol 27(8):631-635

Ip PF, Chen F (2005a) Employment of reactive oxygen species to enhance astaxanthin formation in Chlorella zofingiensis in heterotrophic culture. Process Biochem 40(11):3491-3496. doi:10.1016/j.procbio.2005.02.014

Ip PF, Chen F (2005b) Production of astaxanthin by the green microalga Chlorella zofingiensis in the dark. Process Biochem 40 (2):733-738. doi:10.1016/j.procbio.2004.01.039

Jain R, Raghukumar S, Sambaiah K, Kumon Y, Nakahara T (2007) Docosahexaenoic acid accumulation in thraustochytrids: search for the rationale. Mar Biol 151(5):1657-1664. doi:10.1007/ s00227-007-0608-1

Jakobsen AN, Aasen IM, Josefsen KD, Strom AR (2008) Accumulation of docosahexaenoic acid-rich lipid in thraustochytrid Aurantiochytrium sp strain T66: effects of $\mathrm{N}$ and $\mathrm{P}$ starvation and $\mathrm{O}^{-2}$ limitation. Appl Microbiol Biotechnol 80(2):297-306. doi: 10.1007/s00253-008-1537-8

Javanmardian M, Palsson BO (1991) High density photoautotrophic algal cultures - design, construction, and operation of a novel photobioreactor system. Biotechnol Bioeng 38 (10): 1182-1189

Jiang Y, Chen F (2000) Effects of medium glucose concentration and $\mathrm{pH}$ on docosahexaenoic acid content of heterotrophic Crypthecodinium cohnii. Process Biochem 35(10):1205-1209

Kiy T, Lui M, Zeumer O (2008) Production of omega-3 fatty acids in microflora of thraustochytriales using modified media. Patent WO 2008/049512 A1
Klausmeier CA, Litchman E, Daufresne T, Levin SA (2008) Phytoplankton stoichiometry. Ecol Res 23(3):479-485. doi:10.1007/s11284-008-0470-8

Kobayashi M, Kakizono T, Nagai S (1993) Enhanced carotenoid biosynthesis by oxidative stress in acetate induced cyst cells of a green unicellular alga, Haematococcus pluvialis. Appl Environ Microbiol 59(3):867-873

Kyle DJ, Gladue RM (1991) Eicosapentaenoic acids and methods for their production. Patent WO 91/14427

Kyle DJ, Reeb SE, Sicotte VJ (1991) Docosahexaenoic acid, methods for its production and compounds containing the same. Patent WO 91/11918

Lee YK (1997) Commercial production of microalgae in the AsiaPacific rim. J Appl Phycol 9(5):403-411

Lee YK (2001) Microalgal mass culture systems and methods: their limitation and potential. J Appl Phycol 13(4):307-315

Lee YK (2004) Algal nutrition: heterotrophic carbon nutrition. In: Richmond A (ed) Handbook of microalgal culture: biotechnology and applied phycology. Blackwell, Oxford, pp 116124

Leon-Banares R, Gonzalez-Ballester D, Galvan A, Fernandez E (2004) Transgenic microalgae as green cell-factories. Trends Biotechnol 22(1):45-52. doi:10.1016/j.tibtech.2003.11.003

Lewin J, Lewin RA (1967) Culture and nutrition of some apochlorotic diatoms of genus Nitzschia. J Gen Microbiol 46:361

Liang YN, Sarkany N, Cui Y (2009) Biomass and lipid productivities of Chlorella vulgaris under autotrophic, heterotrophic and mixotrophic growth conditions. Biotechnol Lett 31(7):10431049. doi:10.1007/s10529-009-9975-7

Liu XJ, Duan SS, Li AF, Xu N, Cai ZP, Hu ZX (2009) Effects of organic carbon sources on growth, photosynthesis, and respiration of Phaeodactylum tricornutum. J Appl Phycol 21(2):239246. doi:10.1007/s10811-008-9355-Z

Lv JM, Cheng LH, Xu XH, Zhang L, Chen HL (2010) Enhanced lipid production of Chlorella vulgaris by adjustment of cultivation conditions. Bioresour Technol 101(17):6797-6804. doi:10.1016/ j.biortech.2010.03.120

Lynn SG, Kilham SS, Kreeger DA, Interlandi SJ (2000) Effect of nutrient availability on the biochemical and elemental stoichiometry in the freshwater diatom Stephanodiscus minutulus (Bacillariophyceae). J Phycol 36(3):510-522

Ma RYN, Chen F (2001) Induction of astaxanthin formation in the green microalga Chlorococcum sp by reactive oxygen species (ROS) under mixotrophic conditions of growth. In: Chen F, Jiang Y (eds) Algae and their biotechnological potential. Kluwer Academic, Dordrecht, pp 519-523

Mandalam RK, Palsson BO (1998) Elemental balancing of biomass and medium composition enhances growth capacity in highdensity Chlorella vulgaris cultures. Biotechnol Bioeng 59 (5):605-611

Mendes A, Guerra P, Madeira V, Ruano F, da Silva TL, Reis A (2007) Study of docosahexaenoic acid production by the heterotrophic microalga Crypthecodinium cohnii CCMP 316 using carob pulp as a promising carbon source. World J Microbiol Biotechnol 23 (9):1209-1215. doi:10.1007/s11274-007-9349-z

Mendes A, Reis A, Vasconcelos R, Guerra P, Lopes da Silva T (2009) Crypthecodinium cohnii with emphasis on DHA production: a review. J Appl Phycol 21:199-214. doi:10.1007/s10811-0089351-3

Molina Grima EM, Belarbi EH, Fernandez FGA, Medina AR, Chisti Y (2003) Recovery of microalgal biomass and metabolites: process options and economics. Biotechnol Adv 20(7-8):491515

Ogawa T, Aiba S (1981) Bioenergetic analysis of mixotrophic growth in Chlorella vulgaris and Scenedesmus acutus. Biotechnol Bioeng 23(5):1121-1132 
Ogbonna JC, Tomiyama S, Tanaka H (1998) Heterotrophic cultivation of Euglena gracilis $\mathrm{Z}$ for efficient production of alphatocopherol. J Appl Phycol 10(1):67-74

O'Grady J, Morgan JA (2011) Heterotrophic growth and lipid production of Chlorella protothecoides on glycerol. Bioprocess Biosyst Eng 34(1):121-125. doi:10.1007/s00449-010-0474-y

Oh-Hama T, Miyachi S (1988) Chlorella. In: Borowitzka MA, Borowitzka LJ (eds) Microalgal biotechnology. Cambridge University Press, Cambridge, pp 3-26

Olaizola M (2003) Commercial development of microalgal biotechnology: from the test tube to the marketplace. Biomol Eng 20 (4 6):459-466. doi:10.1016/S1389-0344(03)00076-5

Parker MS, Mock T, Armbrust EV (2008) Genomic insights into marine microalgae. Annu Rev Genet 42:619-645. doi:10.1146/ annurev.genet.42.110807.091417

Perez-Garcia O, Escalante FM, de-Bashan LE, Bashan Y (2011) Heterotrophic cultures of microalgae: metabolism and potential products. Water Res 45(1):11-36. doi:10.1016/j.watres.2010.08.037

Potvin G, Zhang Z (2010) Strategies for high-level recombinant protein expression in transgenic microalgae: A review. Biotech Adv 28:910-918. doi:10.1016/j.biotechadv.2010.08.006

Pulz O, Gross W (2004) Valuable products from biotechnology of microalgae. Appl Microbiol Biotechnol 65(6):635-648. doi:10.1007/s00253-004-1647-x

Quigg A, Finkel ZV, Irwin AJ, Rosenthal Y, Ho TY, Reinfelder JR, Schofield O, Morel FM, Falkowski PG (2003) The evolutionary inheritance of elemental stoichiometry in marine phytoplankton. Nature 425(6955):291-294. doi:10.1038/nature01953

Raja R, Hemaiswarya S, Kumar NA, Sridhar S, Rengasamy R (2008) A perspective on the biotechnological potential of microalgae. Crit Rev Microbiol 34(2):77-88. doi:10.1080/ 10408410802086783

Ramus J (1972) Production of extracellular polysaccharide by unicellular red alga Porphyridium aerugineum. J Phycol 8 (1):97-111. doi:10.1111/j.1529-8817.1972.tb04007.x

Reitan KI, Rainuzzo JR, Olsen Y (1994) Effect of nutrient limitation on fatty acid and lipid content of marine microalgae. J Phycol 30 (6): $972-979$

Riesenberg D, Guthke R (1999) High-cell-density cultivation of microorganisms. Appl Microbiol Biotechnol 51(4):422-430

Rodolfi L, Chini Zittelli G, Bassi N, Padovani G, Biondi N, Bonini G, Tredici MR (2009) Microalgae for oil: strain selection, induction of lipid synthesis and outdoor mass cultivation in a low-cost photobioreactor. Biotechnol Bioeng 102(1):100-112. doi:10.1002/bit.22033

Rosenberg JN, Oyler GA, Wilkinson L, Betenbaugh MJ (2008) A green light for engineered algae: redirecting metabolism to fuel a biotechnology revolution. Curr Opin Biotechnol 19(5):430-436. doi:10.1016/j.copbio.2008.07.008

Running JA, Huss RJ, Olson PT (1994) Heterotrophic production of ascorbic-acid by microalgae. J Appl Phycol 6(2):99-104

Running JA, Severson DK, Schneider KJ (2002) Extracellular production of L-ascorbic acid by Chlorella protothecoides, Prototheca species, and mutants of $P$. moriformis during aerobic culturing at low pH. J Ind Microbiol Biotechnol 29(2):93-98. doi:10.1038/sj.jim.7000275

Sansawa H, Endo H (2004) Production of intracellular phytochemicals in Chlorella under heterotrophic conditions. J Biosci Bioeng 98 (6):437-444

Schmidt RA, Wiebe MG, Eriksen NT (2005) Heterotrophic high celldensity fed-batch cultures of the phycocyanin-producing red alga Galdieria sulphuraria. Biotechnol Bioeng 90(1):77-84. doi:10.1002/Bit.20417

Sensen CW, Heimann K, Melkonian M (1993) The production of clonal and axenic cultures of microalgae using fluorescenceactivated cell sorting. Eur J Phycol 28:93-97
Shen Y, Yuan W, Pei Z, Mao E (2010) Heterotrophic culture of Chlorella protothecoides in various nitrogen sources for lipid production. Appl Biochem Biotechnol 160(6):1674-1684. doi:10.1007/s12010-009-8659-Z

Shi XM, Zhang XW, Chen F (2000) Heterotrophic production of biomass and lutein by Chlorella protothecoides on various nitrogen sources. Enzyme Microb Technol 27(3-5):312-318

Shi XM, Jiang Y, Chen F (2002) High-yield production of lutein by the green microalga Chlorella protothecoides in heterotrophic fed-batch culture. Biotechnol Prog 18(4):723-727. doi:10.1021/ bp0101987

Shi XM, Wu ZY, Chen F (2006) Kinetic modeling of lutein production by heterotrophic Chlorella at various $\mathrm{pH}$ and temperatures. Mol Nutr Food Res 50(8):763-768. doi:10.1002/ mnfr.200600037

Sloth JK, Wiebe MG, Eriksen NT (2006) Accumulation of phycocyanin in heterotrophic and mixotrophic cultures of the acidophilic red alga Galdieria sulphuraria. Enzyme Microb Technol 38(12):168-175. doi:10.1016/j.enzmictec.2005.05.010

Specht E, Miyake-Stoner S, Mayfield S (2010) Micro-algae come of age as a platform for recombinant protein production. Biotechnol Lett 32(10):1373-1383. doi:10.1007/s10529-010-0326-5

Spolaore P, Joannis-Cassan C, Duran E, Isambert A (2006) Commercial applications of microalgae. J Biosci Bioeng 101(2):87-96. doi:10.1263/Jbb.101.87

Sun N, Wang Y, Li YT, Huang JC, Chen F (2008) Sugar-based growth, astaxanthin accumulation and carotenogenic transcription of heterotrophic Chlorella zofingiensis (Chlorophyta). Process Biochem 43(11):1288-1292. doi:10.1016/j. procbio.2008.07.014

Surek B, Melkonian M (2004) CCAC - Culture Collection of Algae at the University of Cologne: a new collection of axenic algae with emphasis on flagellates. Nova Hedwig 79:77-92. doi:10.1127/ 0029-5035/2004/0079-0077

Tokusoglu O, Unal MK (2003) Biomass nutrient profiles of three microalgae: Spirulina platensis, Chlorella vulgaris, and Isochrisis galbana. J Food Sci 68(4):1144-1148

Trainor FR (2009) Breaking the habit. Integrating plasticity into taxonomy. Syst Biodivers 7:95-100

Umysová D, Vítová M, Doušková I, Bišová K, Hlavová M, Čížková M, Doucha J, Machát J, Zachleder V (2009) Bioaccumulation and toxicity of selenium compounds in the green alga Scenedesmus quadricauda. BMC Plant Biol 9:58. doi:10.1186/14712229-9-58:1-16

Vonshak A (1986) Laboratory techniques for the cultivation of microalgae. In: Richmond A (ed) Handbook of microalgal mass culture. CRC, Boca Raton, FL, pp 117-145

Walker TL, Collet C, Purton S (2005a) Algal transgenics in the genomic ERA. J Phycol 41(6):1077-1093. doi:10.1111/j.15298817.2005.00133.x

Walker TL, Purton S, Becker DK, Collet C (2005b) Microalgae as bioreactors. Plant Cell Rep 24(11):629-641. doi:10.1007/s00299005-0004-6

Wang Y, Peng J (2008) Growth-associated biosynthesis of astaxanthin in heterotrophic Chlorella zofingiensis (Chlorophyta). World J Microbiol Biotechnol 24(9):1915-1922. doi:10.1007/s11274008-9692-8

Wen ZY, Chen F (2002) Perfusion culture of the diatom Nitzschia laevis for ultra-high yield of eicosapentaenoic acid. Process Biochem 38(4):523-529

Wen ZY, Chen F (2003) Heterotrophic production of eicosapentaenoic acid by microalgae. Biotechnol Adv 21(4):273-294. doi:10.1016/ S0734-9750(03)00051-X

Wen ZY, Jiang Y, Chen F (2002) High cell density culture of the diatom Nitzschia laevis for eicosapentaenoic acid production: fed-batch development. Process Biochem 37(12):1447-1453 
Widjaja A, Chien CC, Ju YH (2009) Study of increasing lipid production from fresh water microalgae Chlorella vulgaris. J Taiwan Inst Chem Eng 40(1):13-20. doi:10.1016/j. jtice.2008.07.007

Wijffels RH (2008) Potential of sponges and microalgae for marine biotechnology. Trends Biotechnol 26(1):26-31. doi:10.1016/j. tibtech.2007.10.002

Wijffels RH, Barbosa MJ (2010) An outlook on microalgal biofuels. Science 329(5993):796-799. doi:10.1126/science.1189003

Wu ZY, Shi XM (2007) Optimization for high-density cultivation of heterotrophic Chlorella based on a hybrid neural network model. Lett Appl Microbiol 44(1):13-18. doi:10.1111/j.1472765X.2006.02038.X

Wu ZY, Shi XM (2008) Rheological properties of Chlorella pyrenoidosa culture grown heterotrophically in a fermentor. J Appl Phycol 20(3):279-282. doi:10.1007/s10811-007-9244-x

Wynn JP, Behrens PW, Sundararajan A, Hansen J, Apt K (2005) Production of single cell oils by dinoflagellates. In: Cohen $\mathrm{Z}$, Ratledge C (eds) Single cell oils. AOCS, Champaign, IL

Xiong W, Li XF, Xiang JY, Wu QY (2008) High-density fermentation of microalga Chlorella protothecoides in bioreactor for microbiodiesel production. Appl Microbiol Biotechnol 78(1):29-36. doi:10.1007/s00253-007-1285-1

Xiong W, Gao C, Yan D, Wu C, Wu Q (2010a) Double CO(2) fixation in photosynthesis-fermentation model enhances algal lipid synthesis for biodiesel production. Bioresour Technol 101 (7):2287-2293. doi:10.1016/j.biortech.2009.11.041
Xiong W, Liu LX, Wu C, Yang C, Wu QY (2010b) C-13-Tracer and gas chromatography-mass spectrometry analyses reveal metabolic flux distribution in the oleaginous microalga Chlorella protothecoides. Plant Physiol 154(2):1001-1011. doi:10.1104/ pp.110.158956

Yongmanitchai W, Ward OP (1991) Growth of and omega-3-fatty-acid production by Phaeodactylum tricornutum under different culture conditions. Appl Environ Microbiol 57(2):419-425

Zaslavskaia LA, Lippmeier JC, Shih C, Ehrhardt D, Grossman AR, Apt KE (2001) Trophic conversion of an obligate photoautotrophic organism through metabolic engineering. Science 292 (5524):2073-2075. doi:10.1126/science.160015

Zhang XW, Chen F, Johns MR (1999a) Kinetic models for heterotrophic growth of Chlamydomonas reinhardtii in batch and fed-batch cultures. Process Biochem 35(3-4):385-389

Zhang XW, Gong XD, Chen F (1999b) Kinetic models for astaxanthin production by high cell density mixotrophic culture of the microalga Haematococcus pluvialis. J Ind Microbiol Biotechnol 23(1):691-696

Zhang XW, Shi XM, Chen F (1999c) A kinetic model for lutein production by the green microalga Chlorella protothecoides in heterotrophic culture. J Ind Microbiol Biotechnol 23(6):503507

Zou N, Zhang CW, Cohen Z, Richmond A (2000) Production of cell mass and eicosapentaenoic acid (EPA) in ultrahigh cell density cultures of Nannochloropsis sp. (Eustigmatophyceae). Eur J Phycol 35(2):127-133 